Proceedings

\title{
Technical-Economic Analysis of a Hybrid Energy Systems Composed of PV and Biomass Obtained from Municipal Solid Waste Connected to the Grid ${ }^{\dagger}$
}

\author{
Daniel-Cornel Balan ${ }^{1, *}$, Sorina-Mihaela Balan ${ }^{2}$ and Juliana Szakacs ${ }^{3}$ \\ 1 Doctoral School, Technical University from Cluj Napoca, 400114 Cluj-Napoca, Romania \\ 2 Strategies, Programs and Projects Department, Dimitrie Cantemir University from Targu Mures, \\ 540139 Targu Mures, Romania; bsorinamihaela@yahoo.com \\ 3 Pharmacy, Science and Technology of Targu Mures, George Emil Palade University of Medicine, \\ 540139 Târgu Mureș, Romania; szjulianna@gmail.com \\ * Correspondence: bdsrl@yahoo.com; Tel.: +40-724-551-156 \\ + Presented at the 14th International Conference on Interdisciplinarity in Engineering-INTER-ENG 2020, \\ Târgu Mureș, Romania, 8-9 October 2020.
}

Published: 10 December 2020

\begin{abstract}
This paper describes the technical-economic analysis of a hybrid renewable energy systems (HRES) connected to the grid, consisting of photovoltaic (PV) source and municipal solid waste (MSW), taking into account economic and technical criteria. Photovoltaic energy and the new technology used for MSW processing have a lower cost and lower environmental impact. The sensitivity analysis shows that improving the rate of return on investment in HRES can be a measure to encourage the use of renewable energies for electricity production, both in terms of costs and environmental impact.
\end{abstract}

Keywords: solar photovoltaic power; biomass; grid-connected hybrid renewable energy system; prosumer

\section{Introduction}

Renewable Energies (RE) are an alternative worth exploring, as they are effective means of preventing and mitigating climate change, with undeniable external benefits in terms of environmental quality and economic value, especially in the case of photovoltaic (PV), wind, and biomass [1]. The main benefits of RE are in terms of environmental performance, as these sources are carbon-free (photovoltaic) or carbon-neutral (biomass), thus being a viable alternative to de-carbonizing energy generation. Another notable benefit of using RE is the re-evaluation of resources currently misused as well as the creation of local job opportunities. Energy waste technologies are beginning to capture the attention of developing countries as a sustainable source of energy in response to the worsening problem of municipal solid waste management. Waste-to-energy refers to the recovery of the energy from waste materials into usable heat, electricity, or fuel. Various WtE approaches are categorized into landfill, thermal treatment, and biological treatment [2]. Investments in waste-to-energy (WtE) technologies are widely discussed in the literature using the traditional valuation methods such as life cycle analysis (LCA), net present value (NPV), internal rate of return (IRR), payback period (PBP), and returns on investment (ROI). These methods do not cover some characteristics for assessing the project in $\mathrm{WtE}$, the level of risk, such as the irreversibility of the investment project, investment risks, and uncertainty in future cash flows. WtE investment decisions are influenced by waste supply, legal and governmental risks, those related to technology, infrastructure, and socio-political and environmental risks [3]. We must not forget that the biomass has the merit of dispatching, which means that biomass energy is controllable and available when it is needed. Combining the photovoltaic system 
with the biomass system could be an efficient way to create a reliable and cost-effective hybrid energy system. Photovoltaic systems are clean, environmentally friendly, and safe energy sources, and their installation has played an important role worldwide. Grid-connected photovoltaic systems can be Building Integrated Systems (BiPV), Distribution Generation (DGPV), and centralized photovoltaic plants. BiPV systems usually provide a specific load and inject the excess energy into the grid. On the other hand, DGPV systems inject all produced energy into the grid without supplying any local load. Grid-connected systems may consist of a PV array only as an energy source or another energy source may be incorporated with the PV array, such as a wind turbine, diesel generator, biomass, or a storage unit. The third type of grid-connected photovoltaic systems is centralized large photovoltaic systems connected to the utility distribution system. The size and performance of photovoltaic systems depend on meteorological data, and the productivity of the PV system is a location-dependent variable that varies depending on the climatic nature of the area. A good knowledge of climatic parameters, such as solar radiation and ambient temperature, is very important to understanding the total energy available for use in a photovoltaic system. The hybridized RE sources (HRES) are usually photovoltaic and wind, combined with battery storage, or diesel engine-generator set to ensure safety in power supply. The alternative of connecting to the electricity grid of HRES with municipal solid waste (MSW) source has been observed in a few cases [4].

This study focuses on a technical-economic analysis of a hybrid energy system for electricity supply to a consumption center, where the electricity grid is available. The grid can be used both for the sale of locally generated surplus energy and for the purchase of electricity depending on the load curve (load demand). If the load demand cannot be met by the hybrid energy system, then the rest of the electricity can be purchased from the grid at purchase price, and if there is an excess of electricity available due to low energy consumption at a certain time in the village, it can be sold to the grid at sell-back price rate to obtain additional income. Thus, the consumption center becomes a center for energy generation, called a prosumer.

This paper proposes to use the MSW, which is a locally available source and the authorities pay for its processing. The novelty of this paper can be justified by the presentation of the solution for obtaining electricity from the technology used in the processing of MSW and the PV system connected to the electricity grid, which is not always $100 \%$ available.

\section{System Description}

The hybrid system connected to the distribution system operator (DSO) of grid is according to Figure 1, with the advantages of the flexibility provided by connection of HRES to the grid (on-grid) and the MSW generator, which can be used as a back-up to the PV system. Components of system include PV module and a biomass system consisting of a gasifier coupled with an internal combustion engine (ICE) generator group.

The MSW processing subsystem has a $250 \mathrm{kWe}$ gasifier-ICE generator to partially cover the average hourly energy demand. The goal is to recycle waste efficiently and use it optimally for energy for solution Waste to energy or Energy generation from waste.

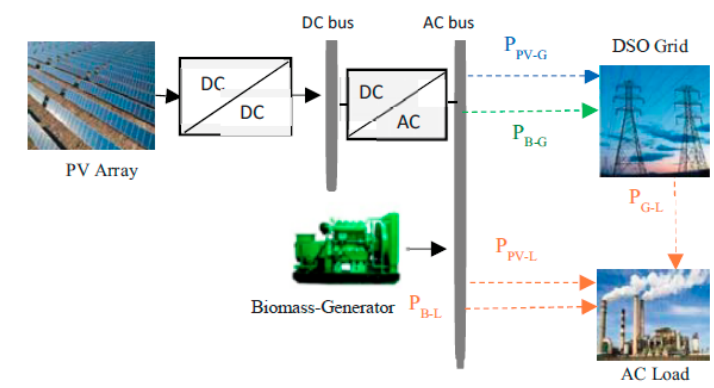

Figure 1. Proposed Photovoltaic (PV)-Biomass Generator on-grid system. 
Through the gasification process, MSW is a raw material for the chemical conversion process, which at high temperature is transformed into a usable gas or syngas, which can be transformed into transport fuel, fertilizer, or can substitute natural gas. The clean syngas obtained by gasification can be used in reciprocating motors or turbines to generate electricity for producing chemicals and liquid fuels [5].

The Waste2Energy plant also has an environmentally friendly advantage: it enables safe disposal at every location and avoids large-scale transport and the storage of large and hazardous waste, as well as noise and smell harassment, and also generates new revenue. By optimizing the hybrid system from a technical and economic point of view, the model can be extended to $1 \mathrm{MW}$ and used in different places, adapting environmental factors, energy demand, component performance, and cost variables to the constraints imposed.

For environmental reasons, this paper proposes to prioritize the use of photovoltaic energy in the time interval 8-16, before the generation of energy from biomass, which is used to support PV whenever it is not available. When total photovoltaic and biomass production is insufficient to match the overall demand, the HRES will consume electricity from the public electrical grid. When photovoltaic energy is sufficient to match the demand, the biomass engine will be reduced to $30 \%$ coefficient of functionality. An intermediate situation occurs when photovoltaic energy exceeds the demand, or when they are not sufficient to supply demand, but starting the biomass subsystem at load generates electricity surplus, and the excess electricity produced is sold to the grid at the market price.

\section{System Component Modeling}

\subsection{Mathematical Model of Biomass Generator}

Biomass, as an energy resource, has a variety of forms, such as municipal solid waste (MSW). A biomass-based generation system consists of biomass preparation unit, biomass gasifier, gas cooling and cleaning system, internal combustion engine, and electric generator. The producer gas obtained from MSW is a feedstock for a high temperature chemical conversion process, as shown in Figure 2.

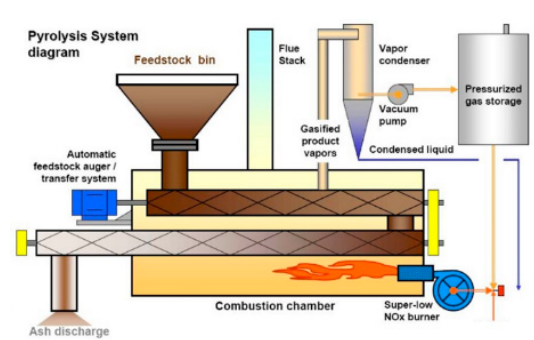

(a)

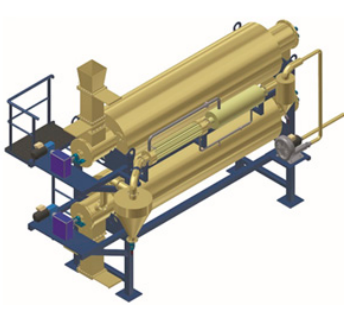

(b)

Figure 2. (a) Schematic of a municipal solid waste (MSW) gasifier and pyrolysis reactor; (b) Pyrolysis reactor.

The annual $(8760 \mathrm{~h})$ delivered electricity production $\left(E_{y e a r}\right)$ of an energy system from MSW gasifier (MSWG), with nominal power of electricity generator is dependent on capacity utilization factor (CUF).

$$
E_{\text {year }}=P_{M S W} * C U F * 8760
$$

where $P_{M S W}$ is the rated power of MSW gasifier (MSWG) system. The maximum size of a MSW gasifier depends on the amount of MSW available, caloric value of MSW, number of hours of usage, and efficiency gasifier system. Following [6], the maximum rating of biomass gasifier can be calculated as Equation (2), where $M_{M S W}$ is the total biomass (Tons/y) available for power generation, $\eta_{M S W G}$ is the efficiency of the MSW gasifier system, $t_{M S W G}$ is the number of operating hours of MSWG system in a day, and $C V_{M S W}$ is the calorific value of the MSW available. 


$$
P_{M S W}^{\max }=\frac{M_{M S W} * 1000 * C V_{M S W} * \eta_{M S W G}}{365 * 860 * t_{M S W G}}
$$

\subsection{Mathematical Model of PV Generator}

According to [7] and using the solar radiation available on the tilted surface of photovoltaic panel, the hourly energy output of the PV generator $\left(E_{P V}\right)$ can be calculated according to hourly irradiance (G) and the following Equation (3), considering the PV system power output (DC) approximately a linear relationship to the insolation.

$$
E_{P V}=G(t) * A * \eta_{P V}
$$

where $E_{\mathrm{PV}}(t)$ is the hourly energy output from PV; $G(t)$ is the hourly irradiance in $\mathrm{kWh} / \mathrm{m}^{2}, A$ is surface area of the PV modules in $\mathrm{m}^{2}, \eta_{P V}$ is the efficiency of PV, and the temperature effects on PV cells are ignored.

\section{Methodology Description}

The following subsections show the steps for choosing the components of the hybrid system connected to the public electrical grid. First, a sample location is selected and then the data needed is determined for the model to identify the optimal compromise between cost and technical constraints and impact in terms of $\mathrm{CO}_{2}$ emissions. Currently, there is no hybrid solar-MSW-pyrolysis plants operating in our country.

\subsection{Sample Selection}

The sample location is a urban township in central Transylvania, with precise geographical coordinates of $46^{\circ} 28^{\prime}$ North and $24^{\circ} 25^{\prime}$ East, a region with high availability of municipal solid waste and a moderate solar irradiation averaging around $1550 \mathrm{kWh} / \mathrm{m}^{2} /$ year. The hourly electricity load averages approximately 1.6 MWh and the hourly peak demand is $2200 \mathrm{kWh}$.

\subsection{Input Data}

Input data are considered as follows: weather-related and demand data, cost and financial variables, equipment efficiency, and performance variables. The data come from trustworthy sources. The solar radiation at ground level, horizontal level was obtained from JRCs' website (European Joint Research Center). This was a starting value to calculate radiation in the modules according to the method indicated by standard UNI 8477/1. Considering the monthly and annual average values for the modules with an inclination of $30^{\circ}$ orientated to south and based on the standards that were mentioned above, the following values were obtained (Table 1).

\begin{tabular}{|c|c|c|c|c|c|c|}
\hline Month & Days & $\varrho$ & $\begin{array}{c}\text { Average Daily } \\
\text { Horizontal } \\
\text { Radiation }\end{array}$ & $\begin{array}{c}\text { Average Daily } \\
\text { Radiation at Tilt } \\
\text { Angle } 30^{\circ}\end{array}$ & $\begin{array}{c}\text { Total Monthly } \\
\text { Horizontal Radiation }\end{array}$ & $\begin{array}{c}\text { Total Monthly } \\
\text { Radiation at Tilt } \\
\text { Angle } 30^{\circ}\end{array}$ \\
\hline & & & {$\left[\mathrm{Wh} / \mathrm{m}^{2}\right.$ day $]$} & {$\left[\mathrm{kWh} / \mathrm{m}^{2}\right.$ day $]$} & {$\left[\mathrm{kWh} / \mathrm{m}^{2}\right]$} & {$\left[\mathrm{kWh} / \mathrm{m}^{2}\right]$} \\
\hline January & 31 & 0.25 & 1.33 & 21.813 & 41.23 & 67.62 \\
\hline February & 28 & 0.25 & 2.1 & 29.987 & 58.80 & 83.96 \\
\hline March & 31 & 0.25 & 3.29 & 40.790 & 101.99 & 126.45 \\
\hline April & 30 & 0.25 & 4.58 & 49.415 & 137.40 & 148.25 \\
\hline May & 31 & 0.25 & 6.08 & 59.757 & 188.48 & 185.25 \\
\hline June & 30 & 0.25 & 6.39 & 60.071 & 191.70 & 180.21 \\
\hline July & 31 & 0.25 & 6.42 & 61.550 & 199.02 & 190.80 \\
\hline August & 31 & 0.25 & 5.92 & 62.008 & 183.52 & 192.22 \\
\hline September & 30 & 0.25 & 4.47 & 53.814 & 134.10 & 161.44 \\
\hline October & 31 & 0.25 & 2.94 & 41.965 & 91.14 & 130.09 \\
\hline November & 30 & 0.25 & 1.56 & 24.895 & 46.80 & 74.69 \\
\hline December & 31 & 0.25 & 1.12 & 19.099 & 34.72 & 59.21 \\
\hline
\end{tabular}

Table 1. Radiation study. 
Table 1. Cont.

\begin{tabular}{|c|c|c|c|c|c|c|}
\hline Month & Days & $\varrho$ & $\begin{array}{c}\text { Average Daily } \\
\text { Horizontal } \\
\text { Radiation }\end{array}$ & $\begin{array}{c}\text { Average Daily } \\
\text { Radiation at Tilt } \\
\text { Angle } 30^{\circ}\end{array}$ & $\begin{array}{c}\text { Total Monthly } \\
\text { Horizontal Radiation }\end{array}$ & $\begin{array}{l}\text { Total Monthly } \\
\text { Radiation at Tilt } \\
\text { Angle } 30^{\circ}\end{array}$ \\
\hline & & & [Wh/m² day] & {$\left[\mathrm{kWh} / \mathrm{m}^{2}\right.$ day $]$} & {$\left[\mathrm{kWh} / \mathrm{m}^{2}\right]$} & {$\left[\mathrm{kWh} / \mathrm{m}^{2}\right]$} \\
\hline $\begin{array}{l}\text { Total } \\
\text { Avarage per day }\end{array}$ & & & & & $\begin{array}{c}1408.9 \\
3.86\left[\mathrm{kWh} / \mathrm{m}^{2} / \text { day }\right]\end{array}$ & $\begin{array}{c}1600.19 \\
4.38\left[\mathrm{kWh} / \mathrm{m}^{2} / \text { day }\right]\end{array}$ \\
\hline
\end{tabular}

The MSW processing pilot project supplies a $250 \mathrm{~kW}$ power generation plant. The aim is to expand MSW processing so that a power of $1 \mathrm{MW}$ can be generated. Processing of fresh municipal waste-at collection points-eliminates air, water, and soil pollution by transforming biomass into pellets. This is done by drying, chopping, and compression into unalterable granules that can be stored for recovery energy by burning there and when needed. For approximately 120,000 inhabitants that collect at least $0.5 \mathrm{Kg}$ of garbage per day, that means 120,000 pers. $\times 0.5 \mathrm{Kg} /$ day $\times 365$ days $=21,900$ tons of household waste/year. From this amount of biomass, by drying, about $35 \%$ is lost, although the following can be achieved: $21,900 \mathrm{t} \times 0.65=14,235$ tons of pellets obtained from municipal waste. Therefore, by processing biomass from municipal waste, the community not only gets rid of the storage of 21,900 tons of garbage but also recovers energy from it 14,235 $\mathrm{t} \times 4.2 \mathrm{Mw} / \mathrm{t}=59,787 \mathrm{Mwh} /$ year.

\subsection{Efficiency and Performance Variables}

Here we include the efficiency of PV modules, auxiliary equipment of PV, and biomass gasification internal combustion engine (ICE) system. The technical characteristics of the PV module (Jinko JKM-250P-60) and SMA Sunny Central SMA 850CP XT-10 inverter used in the studied project are listed in Tables 2 and 3. The PV warranted efficiency curve is used to estimate the PV power output decrease over modules lifetime due to aging (Figure 3).

Table 2. Specifications of the PV module.

\begin{tabular}{cccccc}
\hline Type & Voc (V) & Isc (A) & $\operatorname{Vmax}($ V) & $\operatorname{Imax}(A)$ & $\operatorname{Pmax}(W)$ \\
\hline JKM250P & 37.6 & 8.81 & 30.4 & 8.23 & 250 \\
\hline
\end{tabular}

Table 3. Efficiency and performance variables.

\begin{tabular}{lc}
\hline \multicolumn{1}{c}{ Data } & Value \\
\hline PV module reference efficiency & $15.27 \%$ \\
PV inverter efficiency & $98.4 \%$ \\
PV module mismatch factor & $98.00 \%$ \\
PV connections efficiency & $99.50 \%$ \\
PV DC wiring losses factor & $98.00 \%$ \\
PV AC wiring losses factor & $99.00 \%$ \\
PV soiling derating factor & $95.00 \%$ \\
PV system availability O\&M & $99.00 \%$ \\
Nominal DC system efficiency & $83.9 \%$ \\
Nominal AC system efficiency & $97.4 \%$ \\
Biomass gasifier operation efficiency & $95 \%$ \\
\hline
\end{tabular}

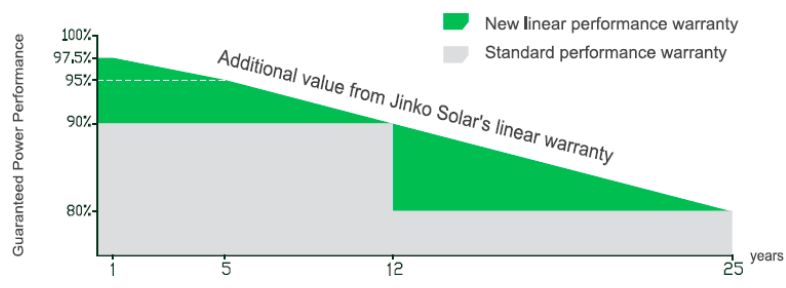

Figure 3. Premium performance warranty [8]. 
The device processes $24 \mathrm{t}$ per day; the municipal waste is shredded by an integrated shredder. Energy recovery: with dry waste about $1 \mathrm{t}=1$ MWh and with wet waste approx. (2.5-3) $t=500 \mathrm{~m}^{3} / \mathrm{h}=$ $1 \mathrm{MWh}$. Another advantage of the system is that its operation requires no significant expertise and has a small footprint (plant $150 \mathrm{~m}^{2}$, arrival and departure and storage area $850-1350 \mathrm{~m}^{2}$ ).

\subsection{Cost and Financial Components}

The cost components include the purchasing cost of PV modules, invertors, biomass gasifier and gas cleaning systems, and the ICE-generator equipment. The implementation of an investment project shall undoubtedly generate expenses that shall have to be exigently and pertinently analyzed. Some of these expenses are exclusively generated by the operation of the investment objective, and others by the legislation in force, especially with regard to the taxes and impositions owed to the state budget or local budget.

\subsubsection{Operating Expenses}

The group of expenses regarding materials and raw materials comprises sub-groups according to the structure analyzed, cash-flow, and budget of revenues and expenses:

- $\quad$ expenses regarding raw materials

- expenses regarding fuels

- $\quad$ expenses regarding spare parts

- $\quad$ expenses regarding other consumable materials

- expenses regarding inventory objects.

Expenses related to personnel, including the expenses related to social security, refers to the necessary personnel that serve the operation under good conditions of the electric energy production equipment, with the mention that we have also considered the fact that this equipment shall operate $24 \mathrm{~h}$ a day. To the operational expenses is added expenses related to social insurance (social security contribution $-20.80 \%$; health social insurance contribution $-5.20 \%$; medical leave fund contribution $-0.85 \%$; unemployment fund contribution $-0.50 \%$; contribution for accident and professional disease insurance $-0.80 \%$ ), expenses related to rent and concession, expenses related to utilities, expenses related to transport, to fees and charges, to commercial and advertising, expenses regarding maintenance and repairs, to insurance, related to the amortization of fixed assets, and expenses related to impositions and taxes.

\subsubsection{Financial Expenses}

The financial expenses are made up of the interests corresponding to the credit, the interest taken into consideration, here being $4.00 \% /$ year/balance. The applicant does not pay in year 1 any interest and any installment, the obligations towards the employer running from year 2 of the investment operation. The expenses regarding interests have been appropriately taken over both in year 2 as well as in years 3-8 of the time interval plotted into the analysis. The key variables determined with regard to the financial results of this project are:

- update rate

- credit interest

- cost of the machines purchased by the project

- cost of salaries of the employed personnel following the project implementation

- revenues achieved from the support schemes.

\section{Case Study}

This case study presents the results obtained at the moment for the promotion of a hybrid electricity generation system consisting of PV and biomass (MSW). A $250 \mathrm{~kW}$ power generation plant from MSW 
processing was built. Presented also are the technical and financial elements related to the $2.5 \mathrm{MW}$ photovoltaic power plant, which can supply part of the energy demand.

\subsection{Biomass System, Pyrolysis Capital, and Operating Costs}

Household waste brought to the platform is introduced into a grinding system (Figure 4a) using a conveyor belt. The grinding system has a capacity of $3000 \mathrm{~kg} / \mathrm{hour}$, from which $3000 \mathrm{~kg} / \mathrm{h}$ shredded waste is obtained. The ground waste is placed in a rotary dryer (Figure $4 \mathrm{~b}$ ) to obtain the necessary moisture for pelletizing.

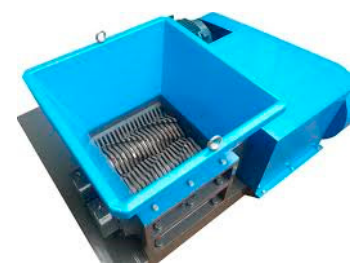

(a)

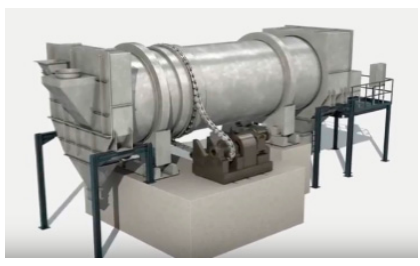

(b)

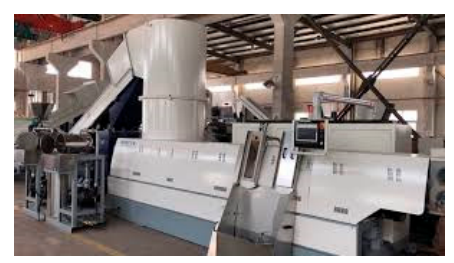

(c)

Figure 4. (a) Grinding plant; (b) Rotary dryer; (c) Pelletizer.

A quantity of $2983.05 \mathrm{~kg} / \mathrm{h}$ of ground waste is introduced, with an average humidity of $53.46 \%$, from which $1500 \mathrm{~kg} / \mathrm{h}$ of ground and dried waste, with a humidity of $9.25 \%$, is obtained. The ground and dried waste is introduced into the pelletizer (Figure 4c), obtaining $1500 \mathrm{~kg} / \mathrm{h}$ pellets. After pelleting, the pellets are introduced into the pyrolysis reactor (Figure $4 \mathrm{~b}$ ). The pellets are introduced by means of a conveyor belt into a reactor heated to the temperature required for pyrolysis. With the high temperature, the thermal decomposition is achieved, and the resulting gases are passed through a complex purification system. The hot gases are first passed through a fine cyclone separating the carbon dust and then directed to a cooling system, where it is cooled to $50{ }^{\circ} \mathrm{C}$. The gases pass through an alternative wet and dry filtration system and are stored in a pressure vessel using a high-performance compressor. It is obtained $500 \mathrm{~m}^{3}$ syngas/hour and max. $12 \%$ coal (ash), $166.62 \mathrm{~kg} /$ hour. The pyrolysis reactor is a major energy consumer, as the reactor must be maintained at $550-600{ }^{\circ} \mathrm{C}$ in the continuous processing of MSW wet raw material. Continuous heat supply is achieved by burning secondary coal, which is a conventional approach used in most industrial pyrolysis systems. From $500 \mathrm{~m}^{3}$ of resulting gases, 1 MWh of electricity can be obtained, from which a power of $80-120 \mathrm{~kW}$ is used for the operation of the equipment. The investment cost for a $1 \mathrm{MW}$ electrical power are 4.821 .880 euro with $19 \% \mathrm{VAT}$, as shown in Table 4.

Table 4. MSW investment cost.

\begin{tabular}{lc}
\hline \multicolumn{2}{c}{ Costs of Basic Investment (Euro with 19\% VAT) } \\
\hline Buildings, constructions, installations & 35,700 \\
Buildings, constructions and installations related to operation of machinery & 23,800 \\
Buildings, constructions, installations related to labor safety and protection & 11,900 \\
Assembly of technological machinery & 11,900 \\
Machinery, equipment with assembly & $4,760,000$ \\
Machinery land transportation & 2380 \\
Software for technological machinery & 11,900 \\
Total Cost & $4,857,580$ \\
\hline
\end{tabular}

Consistent with the known daily energy demand, the solar photovoltaic installation is dimensioned so that the maximum power of $\mathrm{PV}$ to generate electricity is equal to the maximum daily energy demand minus the amount of electricity that can be generated by the MSW-based biomass installation (pyrolysis unit). This then sets the proportion of the total energy demand that will be supplied by the solar PV plant, as well as the solar PV output for each hour in the day. The pyrolysis unit can operate 
continuously, generating syngas that can be stored in a tank and used to power the engine/generator unit when required (Figure 5).

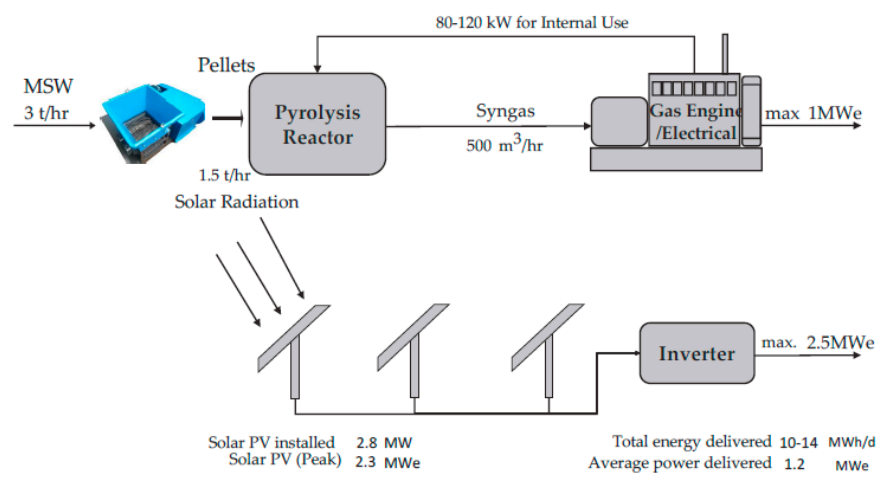

Figure 5. Integration of syngas production and solar PV.

\subsection{Solar PV Unit Capital and Operating Costs}

The generator of the power plant consists of 11.976 single polycrystalline solar modules, each with an electrical peak power of 250 watts, in total 2994 kilowatts. The modules are mounted on a substructure, which is founded on poles rammed into the earth. Twenty-four modules are connected in series to reach higher DC voltages up to max. $1000 \mathrm{~V}$. Two of these module strings are connected parallel to reduce cabling. The PV power plant consists of three inverters in total with an AC output power up to max. $935 \mathrm{kVA}$ each. The type of the inverter is SMA Sunny Central 850CP-10 [9]. The inverters are housed in weatherproofed steel cabinets. These steel cabinets are founded on metal poles rammed into the earth. Six string combiners are connected to one inverter. The inverters are converting the DC current into three-phase AC current with a voltage of 386 volts. For monitoring and control reasons, there will be installed a fiberoptic ethernet to connect all monitoring components (SMA SC-COM/Webbox/Cluster Controller) with the router located in transformer station one. In Romania, starting with 2013, the average leveled costs of electricity from photovoltaic energy decreased from 1.1 euro/W to 0.80 euro/ $\mathrm{W}$ in 2020, being in continuous decrease due to the decrease of prices for photovoltaic modules, inverters, and cost-effective project management and execution. The first two factors that are contributors to the total cost of the PV installation are the photovoltaic modules and mounting system, to which are added the inverters, the substation connection, and the construction labor (Table 5). The operating and maintenance (OPEX) costs of the PV solar power plant are estimated at $2 \%$ of the capital per year and also include insurance, administration, and monitoring PV costs.

Table 5. PV total installed capital cost.

\begin{tabular}{lc}
\hline Item & Cost (Euro/W) \\
\hline Modules & 0.45 \\
Mounting system & 0.08 \\
Electrical system & 0.09 \\
Inverters & 0.26 \\
Construction labour & 0.08 \\
Spares & 0.01 \\
Owners engineering & 0.03 \\
Contingency & 0.08 \\
Total installed capital cost & 1.08 \\
\hline
\end{tabular}

\section{Techno-Economic Results}

The energy generated by the Photovoltaic Power Plant (2.5 MW) located in the coordinates specified in Section 4.1 (Table 6) and the $250 \mathrm{~kW}$ installation obtained from the MSW processing inside 
the consumer lead to the promotion of a hybrid PV-MSW on grid system to ensure energy demand, as shown in Table 7. The environmental conditions are favorable for the operation of the photovoltaic installation, as evidenced by the energy production recorded over the period 2013-2020 (Table 6) [10].

Table 6. Total yield (MWh).

\begin{tabular}{lccccccccccccc}
\hline & Jan. & Feb. & Mar. & Apr. & May & Jun. & Jul. & Aug. & Sep. & Oct. & Nov. & Dec. & Total \\
\hline 2013 & & & & & & & 423.8 & 453.1 & 316.18 & 294.7 & 170.8 & 112.42 & 1770.9 \\
2014 & 88.92 & 208.1 & 373.9 & 353.21 & 471.9 & 455.8 & 447.4 & 467.9 & 400.38 & 277.7 & 150 & 105.61 & 3800.9 \\
2015 & 118.9 & 233.7 & 330.2 & 388.35 & 435.2 & 459.7 & 517 & 458.2 & 296.06 & 248.5 & 133.8 & 78.48 & 3698.1 \\
2016 & 116.1 & 182.3 & 294.3 & 400.67 & 422.5 & 466.1 & 494.7 & 443.6 & 374.87 & 189.7 & 151.4 & 102.38 & 3638.7 \\
2017 & 150.6 & 171.8 & 356.6 & 392.26 & 441.3 & 478.7 & 496.8 & 470.1 & 337.89 & 255.1 & 97.9 & 66.92 & 3715.8 \\
2018 & 141.5 & 128.1 & 238.5 & 420.44 & 487.6 & 407.6 & 415.9 & 484 & 349.31 & 304.5 & 160.2 & 64.64 & 3602.2 \\
2019 & 90.21 & 185.8 & 369.7 & 387.87 & 379.1 & 472.8 & 440.2 & 447.2 & 370.75 & 310.1 & 150.9 & 100.04 & 3704.7 \\
2020 & 95.83 & 182.9 & 297.5 & 464.76 & 380.4 & 332 & 435.6 & 441.9 & 360.59 & 199.7 & 80.78 & 38.12 & 3310.2 \\
\hline
\end{tabular}

Table 7. The evolution of power.

\begin{tabular}{cccccc}
\hline $\mathbf{P}$ & $\mathbf{2 0 2 0}$ & $\mathbf{2 0 2 1}$ & $\mathbf{2 0 2 2}$ & $\mathbf{2 0 2 3}$ & $\mathbf{2 0 2 4}$ \\
\hline MW & 1.6 & 2.5 & 3.2 & 3.6 & 4 \\
\hline
\end{tabular}

The techno-economic analysis for the photovoltaic and MSW-based installation is undertaken using a discounted cash flow (DCF) model. In the technical and economic analyzes, the increase of energy consumption was taken into account. Thus, from a power of 1.6 MW, it will reach a power of $4 \mathrm{MW}$ (Table 7). The feasibility study prepared showed that from MSW installation and according to the sale price agreed by both parties (DSO electric operator and beneficiary) of 45.00 euro/MWh and taking into account the fact that the equipment can operate $24 \mathrm{~h}$ a day, it results in a power of $24 \mathrm{MW}$ that can be generated per day, some of which are distributed locally and the surplus energy will be delivered on the grid. Following the processing of biomass and achievement of electric energy, the result is a quantity of residual product (ashes) in a percentage of $16 \%$ of the processed biomass quantity. The residual product achieved, in combination with other additives, represents raw material for obtaining cement; consequently it can be valorized as such. Furthermore, the applicant may opt for an association for producing cement and this can be subsequently valorized. In calculating the performed analysis, we have opted for the valorization in raw condition of the residual product, the sale price being established as being 20-25 euro/ton. The resulting financial indicators for a $1 \mathrm{MW}$ plant generating electricity from MSW processing lead to a favorable investment and the investment can support its own cost, the operation cost and, more than that, also generate a profit.

\section{Conclusions}

The hybrid system described, consisting of photovoltaic sources and municipal solid waste connected to the electricity network of the distributor, is a feasible source that can provide energy at competitive prices. For the power required in the next period, it will be necessary to analyze the technical options for expanding the processing capacity of MSW and providing electricity from the biomass plant. In this regard, it would be advisable to analyze the heat recovery solution and its use to power a motor for electricity generation, when the situation requires it. The development of the solar PV and MSW energy systems will require a stable and reasonably priced supply of biomass in areas where the solar yield is attractive. While the solar PV and MSW system analyzed in this work will likely be a niche solution, it offers a credible starting point for the development of larger-scale bio-energy value chains, with the longer term goal of converting MSW materials into renewable transportation fuels and chemicals. 


\section{References}

1. Zhao, H.; Guo, S. External benefit evaluation of renewable energy power in China for sustainability. Sustainability 2015, 7, 4783-4805. [CrossRef]

2. Kumar, A.; Samadder, S.R. A review on technological options of waste to energy for effective management of municipal solid waste. Waste Manag. 2017, 69, 407-422. [CrossRef] [PubMed]

3. Ferdan, T.; Šomplák, R.; Zavíralová, L.; Pavlas, M.; Frýba, L. A waste-to-energy project: A complex approach towards the assessment of investment risks. Appl. Therm. Eng. 2015, 89, 1127-1136. [CrossRef]

4. González, A.; Riba, J.R.; Rius, A. Optimal sizing of a hybrid grid-connected photovoltaic-wind-biomass power system. Sustainability 2015, 7, 12787-12806. [CrossRef]

5. Vishal, S.; Vatsal, N. Gasification-A Process for Energy Recovery and Disposal of Municipal Solid Waste. Am. J. Mod. Energy 2016, 2, 38-42.

6. Gupta, A.; Saini, R.P.; Sharma, M.P. Steady-state modelling of hybrid energy system for off grid electrification. Renew. Energy 2010, 35, 520-535. [CrossRef]

7. Diaf, S.; Diaf, D.; Balha, M.; Hahhadi, M. A methodology for optimal sizing of autonomous hybrid PV/wind system. Energy Policy 2007, 35, 5708-5718. [CrossRef]

8. Available online: https://keysolar.com.au/wp-content/uploads/2014/07/Jinko-Poly250W.pdf (accessed on 11 June 2012).

9. Available online: http://files.sma.de/dl/18859/SC800CP-900CP-DEN1751-V23web.pdf (accessed on 11 June 2012).

10. Balan, D. Behavior of photovoltaic systems connected to the distribution network. Case study, photovoltaic power plants in the distribution network of the SDEE Mures operator. Procedia Manuf. 2018, 803-810. [CrossRef]

Publisher's Note: MDPI stays neutral with regard to jurisdictional claims in published maps and institutional affiliations.

(C) 2020 by the authors. Licensee MDPI, Basel, Switzerland. This article is an open access article distributed under the terms and conditions of the Creative Commons Attribution (CC BY) license (http://creativecommons.org/licenses/by/4.0/). 